\title{
LHCGR Gene Mutation
}

National Cancer Institute

\section{Source}

National Cancer Institute. LHCGR Gene Mutation. NCI Thesaurus. Code C158720.

A change in the nucleotide sequence of the LHCGR gene. 